\title{
AOIR
}

Selected Papers of \#AolR2021:

The 22nd Annual Conference of the

Association of Internet Researchers

Virtual Event / 13-16 Oct 2021

\section{ALGORITHMIC IMAGINARIES IN THE MAKING: BRAZILIAN UBERTUBERS ENCOUNTERS WITH SURGE PRICING ALGORITHMS}

\author{
Ana Guerra \\ Universidade Federal de Minas Gerais \\ Carlos Frederico de Brito D'Andréa \\ Universidade Federal de Minas Gerais
}

\section{Introduction}

Surge pricing (SP) is a central mediator of Uber driver's everyday experience. It can be described as an algorithmically driven mechanism that uses price adjustments as financial incentives to redistribute the workforce on a territory (Rosenblat; Stark, 2016). SP algorithms are presented by Uber as entities capable of measuring, translating, and responding to the market conditions - roughly summarized as drivers' supply and riders' demand. A heatmap with colored shades shown in the "Uber Driver" app orients the 'real-time' decisions made by the platform workers (Grohmann; Qiu, 2020).

This algorithmic governance is routinely questioned and appropriated by drivers. Although SP may trigger feelings of excitement, it is also often associated with frustration and deception, for example when SP disappears as soon as they reach high-demand areas. Receiving requests from riders outside surge areas or the non-payment of the extra value are some of the issues faced and discussed by Uber drivers.

This paper argues that drivers' everyday practices and efforts to understand and contest surge pricing are productive of algorithmic imaginaries and valid forms of knowledge (Bucher, 2018) that, based on personal and shared experiences, inform how they orient their actions towards Uber's algorithmic systems. We approach this by mapping and analyzing how popular Brazilian Uber drivers discuss surge pricing on their YouTube channels. Our focus is understanding how these "Ubertubers" - drivers who built their YouTube presence based on their identity as Uber drivers - explain and demonstrate how SP works, producing and sharing their own visual inscriptions (Latour, 1999).

Inspired by Critical Algorithmic Studies, this paper seeks to contribute to the understanding of the situated knowledge triggered by algorithm-oriented experiences. 
Such experiences are part of what constitutes algorithms' "ontogenic nature" (Kitchin, 2017), as they are continuously edited and updated, as well as transformed by user's practices. By investigating the algorithmic imaginaries of SP, we are interested in "the way in which people imagine, perceive and experience algorithms and what these imaginations make possible" (Bucher, 2017, p. 31), taking into account the productive capacities of people's encounters with these sociotechnical systems ${ }^{1}$.

\section{Uber Drivers on YouTube}

The relevance of videos produced by Ubertubers has been previously pointed out by Chan (2019), who argues that, by positioning themselves as sociotechnical experts, these drivers assume a pedagogical discourse that promises to unpack Uber's systems to optimize driver's earnings and productivity. Thus, Ubertubers are expected to be "self-entrepreneurs" not only as drivers but also in video production and audience engagement.

In previous research (Guerra, 2018), we observed how over 100 Brazilian Ubertubers organize a shared knowledge based on everyday practices. Personal stories about working as an Uber driver, explanations about changes and updates in the app, advice about how to avoid robberies, and calls for collective political action are the most common issues in their videos. Thus, through a performance of expertise, Ubertubers systematize drivers' algorithmic imaginaries and make them accessible to a wider audience.

\section{Findings}

For this study we analyzed 59 videos posted by the seven most popular Brazilian UberTubers (all with more than 50,000 subscribers by the time of channel selection). All of them are men and living in the South or Southeast of Brazil. The time frame of this data collection - October/2016 to October/2020 - allowed us to follow how drivers' perception of SP and SP itself changed over time.

After watching and transcribing the videos, we could identify three main topics:

(a) What is surge pricing and what does it do? To answer this broader question, Ubertubers describe their experience with SP as a mix of excitement and frustration, often depicting it as an "illusion" or a "lure". Their analysis also refers to SP's visual form (the reddish heat map) as a "bleeding screen" or a "screen on fire". Many of the videos are dedicated to explaining, through inscriptions produced by them (screenshots and hand drawings) how SP works and why it often leads to frustration (Fig. 1).

\footnotetext{
${ }^{1}$ This study is part of Ana Guerra's academic master's thesis, which investigates Uber's surge pricing through technographic research methods (Bucher, 2018). This research engaged in the tracing of documents and inscriptions that cluster around SP and account both for the perspective of Uber and drivers.
} 
Figure 1: an Ubertuber uses hand drawings to explain how SP works Source: screenshot produced by the authors

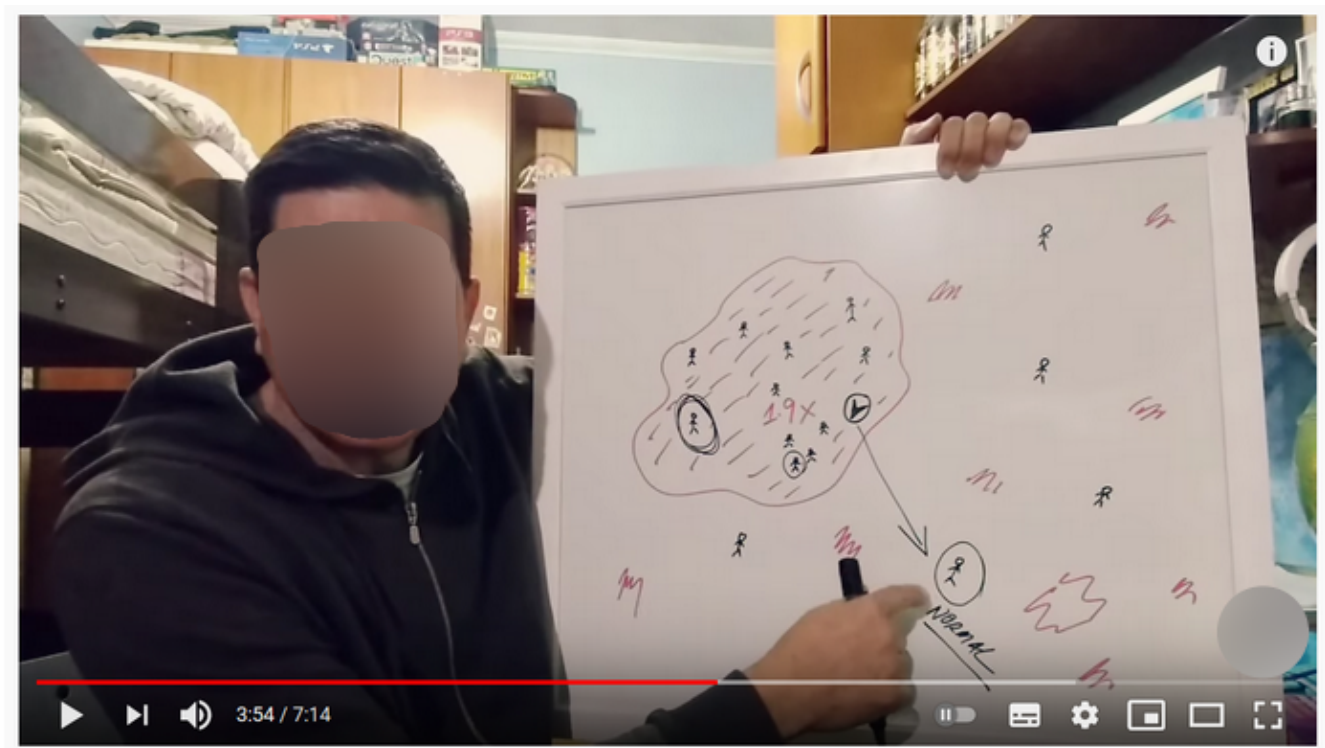

COMO FUNCIONA O DINÂMICO NA UBERI

(b) Tactics to benefit from surge pricing - Ubertubers teach their audience how to work with surge pricing. Uber hides SP once drivers accept a ride, forcing drivers to "work in the dark", as one UberTuber puts it, but they create tactics to make SP visible before they accept the next trip. As a new ride request usually appears before the current ride is completed, the advice is to go offline during rides. Alternatively, one Ubertuber chooses to work with two separate smartphones to permanently track SP. Based on temporal and spatial patterns (e.g. rush hour and the city's center-periphery mobility dynamics), this driver developed his own classification of SP variations.

(c) Algorithmic Labor as a laboratory - SP is constantly updated and various versions are tested on different drivers. Ubertubers continuously document changes on how SP performs - be it how their extra earnings are calculated or how it is displayed on the app's interface. Many of the changes are not officially announced by Uber and are only perceived on driver's everyday encounters with the app. This documentation is done in a collective effort, with Ubertubers often using screenshots and accounts provided by other drivers.

Through the analysis of the videos, we were able to approach how drivers experience and imagine surge pricing algorithms, and how their appropriations negotiate their orientation towards this sociotechnical system. Driver's situated encounters with SP algorithms generate practical knowledge fueled by productive affects. Through the engagement with their audiences, Ubertubers collectivize these experiences and imaginations, potentially transforming how various other drivers incorporate surge pricing into their own tactics and daily routines. 
Finally, Drivers' channels offer us the opportunity to learn from these workers about how SP algorithms act, what they supposedly do and how they transform labor on a micropolitical level. Another contribution to the field is the recognition of this audiovisual material as a singular "archive" of SP's many versions and facets, giving us access to information on algorithms we might have not been able to find otherwise.

\section{References}

Bucher, T. (2018). If... then: Algorithmic Power and Politics. Oxford University Press.

Bucher, T. (2017). The algorithmic imaginary: exploring the ordinary affects of Facebook algorithms. Information, Communication and Society, 20(1), 30-44.

Chan, N. K. (2019). Becoming an expert in driving for Uber": Uber driver/bloggers' performance of expertise and self-presentation on YouTube". New Media and Society, 2019.

Guerra, A. (2018). Plataformização do trabalho: um estudo das redes em ação no trabalho dos motoristas Uber. (Undergraduate thesis). Universidade Federal de Minas Gerais, Belo Horizonte, Brazil.

Guerra, A. (2021). Infraestruturas, narrativas e imaginários algorítmicos: tecnografando o preço dinâmico da Uber (Master's thesis). Universidade Federal de Minas Gerais, Belo Horizonte, Brazil.

Grohmann, R.; Quu, J. (2020). Contextualizing platform labor. Contracampo, 39(1).

Kitchin, R. (2017). Thinking critically about and researching algorithms. Information, Communication \& Society, 20(1),14-29.

Latour, B. (1999). Pandora's Hope: Essays on the Reality of Science Studies (1st edition). Harvard University Press.

Rosenblat, A., Stark L. (2016). Algorithmic Labor and Information Asymmetries: A Case Study of Uber's Drivers. International Journal of Communication, 10,3758-84. 